\title{
Analisa Komposisi Portofolio Kredit pada Bank BNI Sentra Kredit Kecil Bandung dengan Menggunakan Kurva Efficient Frontier
}

\author{
Muhammad Ilham ${ }^{1}$
}

\begin{abstract}
Abstrak
Penelitian ini bertujuan untuk mengetahui komposisi portofolio kredit saat ini pada Bank BNI Sentra Kredit Kecil (SKC) Bandung, menentukan komposisi portofolio kredit yang optimal dan pengaruh komposisi portofolio kredit terhadap return dan risiko kredit.

Sumber data yang digunakan dalam penelitian ini bersumber dari data perkreditan yang dimiliki Bank BNI Sentra Kredit Kecil (SKC) Bandung. Jenis data yang digunakan adalah data sekunder, mencakup data bulanan posisi kredit yang diklasifikasikan dalam beberapa sektor ekonomi. Pada penelitian ini penulis mengambil data perkreditan sejak bulan Januari 2010 s/d Maret 2011. Data penelitian yang diambil selama kurun waktu tersebut karena ingin mengetahui komposisi portofolio kredit terkini pada Bank BNI Sentra Kredit Kecil (SKC) Bandung. Metode yang digunakan pada penelitian ini adalah metode Markowitz. Metode ini didasarkan pada teorema sederhana yang disebut dengan efficient set theorem yaitu investor akan memilih portofolio yang optimal dari sekumpulan portofolio yang memberikan expected return yang paling maksimum pada berbagai tingkat risiko dan/atau yang memberikan risiko yang minimum pada berbagai tingkat expected return.

Hasil yang diperoleh dari penelitian menunjukkan bahwa pengelolaan portofolio kredit yang dilakukan oleh Bank BNI Sentra Kredit Kecil (SKC) Bandung masih jauh dari komposisi portofolio kredit yang optimal. Hal ini ditunjukkan dari hasil return yang rendah dan risiko yang tinggi. Berdasarkan kurva efficient frontier yang terbentuk, dapat diketahui bahwa komposisi portofolio kredit yang paling optimal bagi Bank BNI Sentra Kredit Kecil (SKC) Bandung yaitu komposisi portofolio kredit yang menghasilkan expected return 0,450\% dengan standar deviasi 0,000112. Hasil penelitian juga menunjukkan bahwa komposisi portofolio kredit yang optimal akan menghasilkan risiko yang minimal dan return yang maksimal.
\end{abstract}

\section{Kata Kunci : Komposisi Kredit, Metode Markowitz, Return, Risiko Kredit, Sektor Ekonomi}

\section{Pendahuluan}

Bank sebagai sebuah lembaga yang diberikan izin oleh otoritas perbankan untuk menerima simpanan, memberikan kredit, dan menerima serta menerbitkan cek (Badan Sertifikasi Manajemen Risiko 2007), tentunya tidak akan lepas dari risiko pada setiap aktivitas yang ada di dalamnya. Salah satu risiko yang dihadapi oleh bank adalah risiko kredit. Risiko ini merupakan risiko terbesar yang dihadapi bank karena pendapatan bank sebagian besar berasal dari pendapatan bunga kredit. Pendapatan yang berasal dari penyaluran kredit memberikan kontribusi laba yang cukup besar bagi bank.

Perbankan dalam menyalurkan kreditnya melakukan pembagian sektor ekonomi, hal ini lebih dikenal sebagai portofolio kredit. Setiap bank berhak menentukan penyaluran kredit yang akan diberikan pada sektor ekonomi tertentu. Penyebaran portofolio kredit yang dilakukan hampir seluruh bank sampai saat ini masih tetap banyak menimbulkan risiko yang tinggi, meskipun masingmasing bank telah memilih sektor ekonomi apa yang akan diberikan kredit. Pemilihan sektor ekonomi yang akan dibiayai seharusnya turut menjadi perhatian dalam pengelolaan portofolio kredit.

Pengelolaan portofolio kredit pada Bank BNI dilakukan secara sentralisasi dengan implementasinya dilakukan oleh masing-masing cabang/unit bisnis dengan berpedoman kepada kebijakan yang telah ditentukan. Cabang/unit bisnis tidak dikondisikan untuk mengenal dengan baik profil risiko portofolionya masing-masing. Pengenalan risiko yang dijalankan oleh unit bisnis sifatnya masih bersifat individual risk, yaitu risiko yang terkait 
langsung dengan counterpart-nya, dalam hal ini debitur. Saat ini kinerja Bank BNI secara keseluruhan dan Sentra Kredit Kecil (SKC) Bandung sebagai salah satu unit bisnisnya tidak menunjukkan peningkatan yang signifikan.

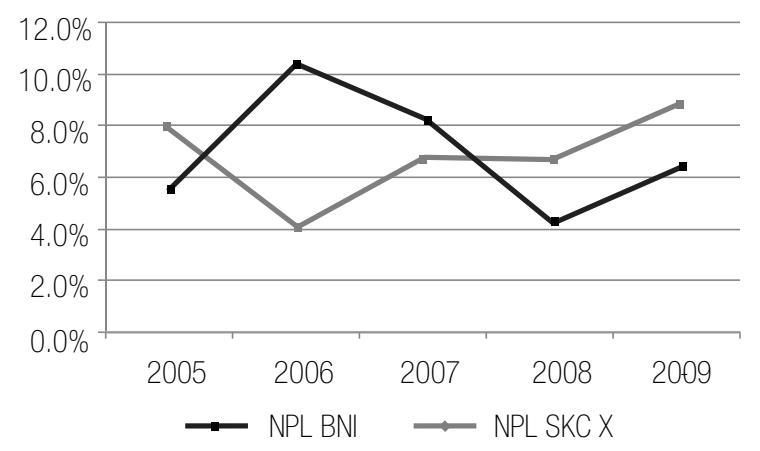

\section{Gambar 1 \\ Posisi Portofolio Kredit Bank BNI keseluruhan dan SKC}

Sumber : Laporan Bank BNI

Dari Gambar 1 di atas, terlihat secara nominal bisnis yang dijalankan oleh Bank BNI secara keseluruhan dan SKC Bandung tetap tumbuh sampai dengan tahun 2008, namun pada tahun 2009 terlihat portofolio kredit SKC Bandung menunjukkan sedikit penurunan sedangkan portofolio kredit Bank BNI secara keseluruhan menunjukkan kenaikan.

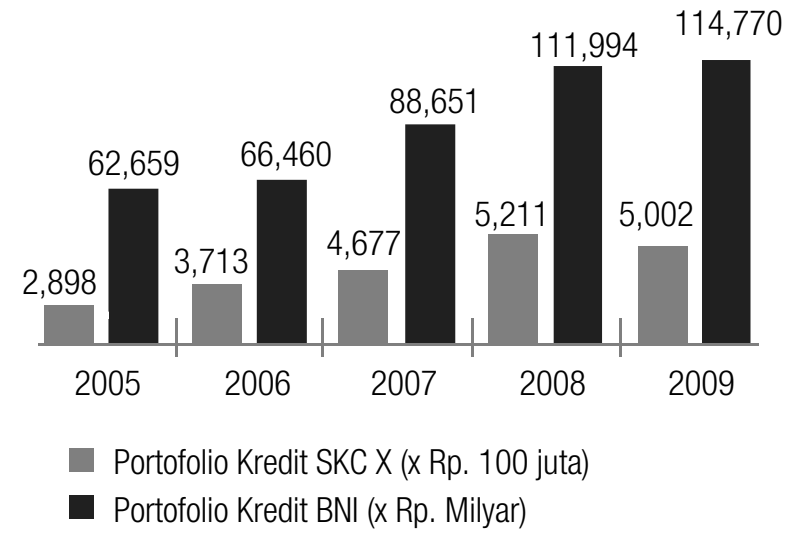

\section{Gambar 2 \\ Posisi Kredit Bermasalah (NPL) Bank BNI Keseluruhan dan SKC}

Sumber : Laporan Bank BNI

Dari Gambar 2 di atas, terlihat bahwa posisi kredit bermasalah/Non-Performing Loan (NPL) Bank BNI secara keseluruhan menunjukkan tren penurunan sejak tahun 2006 s/d 2008 namun sedikit naik pada tahun 2009, sedangkan pada SKC Bandung terlihat posisi kredit bermasalah/NPL menunjukkan tren kenaikan secara konsisten sejak tahun 2006 s/d. 2009.

Berdasarkan hal tersebut di atas, terlihat bahwa SKC Bandung sebagai unit bisnis yang merupakan ujung tombak pemasaran kredit belum dapat memberikan kinerja yang optimal sesuai yang diharapkan. Hal ini antara lain karena kurangnya pengetahuan mengenai profil portofolio kredit kelolaannya, terutama dari sisi risiko dan return.

Kegiatan yang dilakukan SKC Bandung sebagai unit bisnis selama ini hanyalah berupaya meningkatkan jumlah portofolio kredit semaksimal mungkin sehingga risk dan return dari portofolio kredit yang dikelola tidak diketahui dengan pasti oleh SKC Bandung. Hal ini akan dapat menimbulkan risiko dimasa depan karena SKC Bandung sebagai unit bisnis tidak mengenal dengan baik portofolionya mengenai sektor ekonomi mana yang memiliki return yang paling baik dengan risiko yang minimal.

Metode Markowitz yang diperkenalkan oleh Profesor Harry Markowitz dapat mengubah pandangan kaum investor mengenai risiko dengan jalan memperkenalkan konsep risiko secara kuantitatif (Fabozzi 1999). Metode Markowitz ini dapat digunakan untuk menentukan risiko terkecil dari suatu portofolio, tidak hanya saham, namun dapat diterapkan juga pada posisi kredit, dan hal ini merupakan keunggulan dari metode Markowitz.

Dalam pembentukan portofolio, para investor berusaha memaksimalkan pengembalian yang diharapkan dari investasi dengan tingkat risiko tertentu yang dapat diterima (Fabozzi 1999). Dengan kata lain investor berusaha meminimalkan risiko yang dihadapi untuk sasaran tingkat pengembalian tertentu, dimana investor dalam hal ini dapat diasumsikan pula sebagai bank yang memberikan kredit kepada debiturnya. Portofolio yang dapat mencapai tujuan di atas disebut dengan portofolio yang efisien.

Dalam pembentukan suatu portofolio, investor akan membentuk portofolio yang memberikan kombinasi antara return yang maksimum dengan risiko yang minimum. Untuk mendapatkan hal tersebut maka dalam suatu portofolio perlu dilakukan diversifikasi.

Diversifikasi Markowitz berusaha melakukan penggabungan aktiva-aktiva dalam portofolio dengan pengembalian yang memiliki korelasi positif kurang dari sempurna, dengan tujuan mengurangi risiko portofolio 
(varians) tanpa mengurangi pengembalian. Diversifikasi Markowitz tersebut menghasilkan suatu kurva yang menunjukkan suatu set portofolio yang mungkin dibentuk dari aktiva yang ada dengan berbagai tingkat return dan risiko yang dihasilkan dari berbagai komposisinya yang dikenal dengan Markowitz Efficient Frontier (MEF).

\section{Kerangka Pemikiran}

Untuk mampu bertahan dalam bisnisnya, maka bank harus melakukan praktek manajemen risiko secara komprehensif. Risiko yang terbesar yang dihadapi bank adalah risiko kredit, karena portofolio bank masih didominasi oleh kredit begitu pula dalam hal pendapatan. Bank Negara Indonesia (BNI) sebagai salah satu bank terbesar di Indonesia memiliki pendapatan terbesar mencapai $76,2 \%$ berasal dari pendapatan bunga kredit.

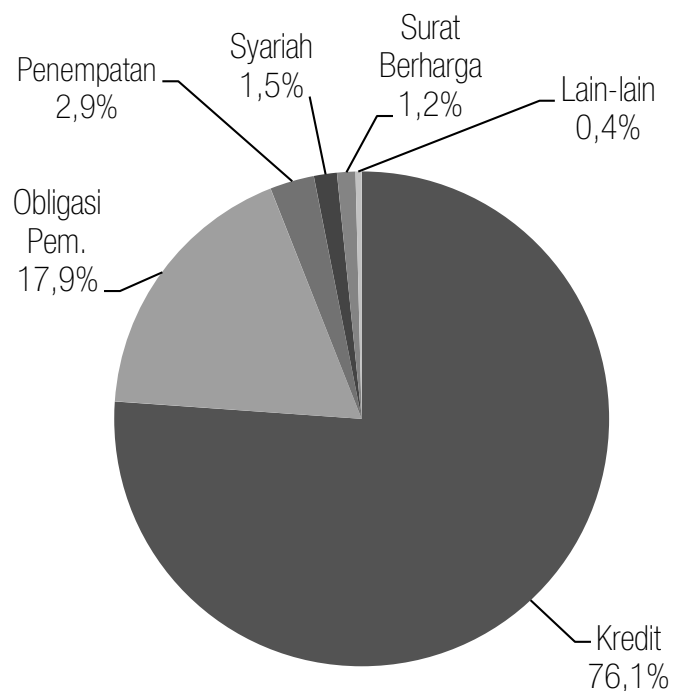

\section{Gambar 3 \\ Kontribusi Pendapatan BNI per Segmen}

Sumber : Sumber BNI

Bank BNI harus mengelola portofolio kreditnya sedemikian rupa agar mampu memberikan kombinasi risk dan return yang optimal. Untuk itu unit bisnis harus mampu mengenali kinerja portolionya dan membentuk suatu komposisi yang optimal dalam mencapai target bisnis yang diberikan.

Salah satu metode yang paling populer dan mendasar dalam manajemen portofolio adalah Teori Portofolio Modern (Modern Porfolio Theory, MPT) yang diperkenalkan oleh Harry Markowitz. Teori ini didasarkan pada teorema sederhana yang disebut dengan efficient set theorem, yaitu: investor akan memilih portofolio yang optimal dari sekumpulan portofolio yang memberikan expected return yang paling maksimum pada berbagai tingkat resiko dan/atau yang memberikan resiko yang minimum pada berbagai tingkat expected return. Pembentukan portofolio ini dilakukan dengan menggabungkan beberapa sekuritas tunggal dengan syarat sekuritas yang dipilih tidak boleh saling berkorelasi positif dan sempurna. Komposisi portofolio yang efisien itu dikenal dengan kurva efficient frontier.

Dari teori tersebut, maka unit bisnis sebagai ujung tombak perbankan dalam mencapai target bisnisnya harus memiliki pengetahuan dan kemampuan untuk mengelola portofolio kreditnya secara optimal. Bagi unit bisnis portofolio kredit yang dimilikinya dapat digolongkan pada beberapa kategori yaitu: berdasarkan sektor ekonomi, berdasarkan jenis kredit dan berdasarkan tiering maksimum kredit. Untuk itu maka harus dilakukan evaluasi terhadap kinerja portofolio kredit yang ada secara historikal, baik resiko maupun returnnya. Setelah itu dapat diformulasikan gambaran komposisi portofolio optimal yang ideal dengan menghasillkan return yang optimal dengan resiko yang wajar dengan berdasarkan efficient frontier yang dibentuk. Sehingga dalam pencapaian target ekspansi kredit yang akan dilakukan, unit bisnis memiliki arahan yang jelas dalam pemilihan portofolionya. Pada penelitian ini pemilihan portofolio kredit yang akan dibentuk adalah berdasarkan sektor ekonomi.

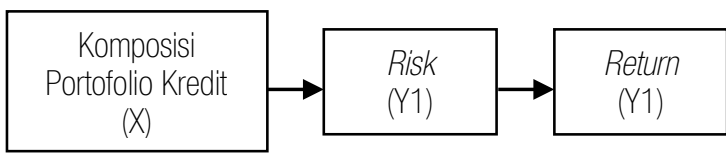

\section{Gambar 4 Paradigma Penelitian}

\section{Metode Penelitian}

Penelitian ini dapat dikategorikan sebagai penelitian ex post facto dan survey explanatory, yakni suatu penelitian yang dilakukan untuk meneliti peristiwa yang telah terjadi. Sedangkan survey explanatory menurut Kerlinger dalam (Sugiyono 2006:7):

"Metode survey yaitu metode penelitian yang dilakukan pada populasi besar maupun kecil, tetapi 
data yang dipelajari adalah data-data dari sample yang diambil dari populasi tersebut, sehingga ditemukan kejadian-kejadian relatif, distribusi, dan hubungan-hubungan antar variabel sosiologis maupun psikologis."

Mengingat jenis dan sifat penelitian ini adalah ex post facto dan survey explanatory, maka metode penelitian yang digunakan adalah metode yang bersifat deskriptif, komparatif, asosiatif, dan juga verifikatif. Penelitian diskriptif dilakukan untuk mengetahui dan menjelaskan karakteristik variabel yang diteliti dalam suatu situasi. Komparatif digunakan untuk membandingkan kurun waktu yang berbeda. Sedangkan asosiatif bertujuan untuk menguji kausalitas antar variabel penelitian (Sekaran 2006:158; Sugiyono 2006:11).

Dalam penelitian ini terdapat dua variabel yang diteliti, yaitu risk dan return sebagai variabel terikat sedangkan komposisi portofolio kredit sebagai variabel bebas,

Tabel 1

Operasionalisasi Variabel Penelitian

\begin{tabular}{|c|l|l|c|c|}
\hline No & \multicolumn{1}{|c|}{ Variabel } & \multicolumn{1}{|c|}{ Indikator } & Satuan & Skala \\
\hline 1. & Komposisi Portofolio Kredit (X) & Jumlah Penyaluran Kredit & $\%$ & Rasio \\
\hline 2. & Risiko Kredit (Y1) & Kredit Bermasalah (NPL) & $\%$ & Rasio \\
\hline 3. & Return Kredit (Y2) & Pendapatan Bunga & $\%$ & Rasio \\
\hline
\end{tabular}

\section{Hasil Pengujian}

\subsection{Pembentukan Kurva Efficient Frontier}

Berdasarkan perhitungan-perhitungan yang telah dilakukan didapatkan hasil berupa kurva efficient frontier berikut ini :

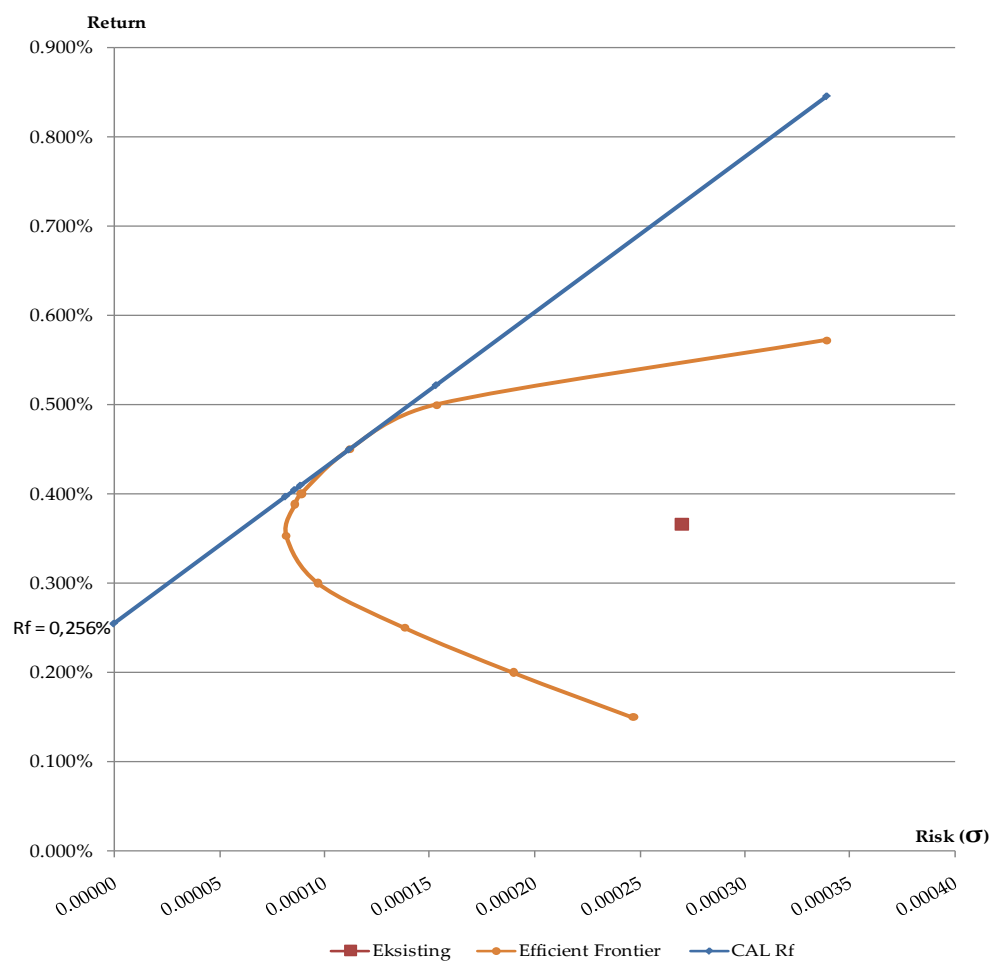

Gambar 5

Efficient Frontier dan CAL 
Dari hasil plotting kurva efficient frontier dan garis CAL tersebut dapat dilketahui bahwa komposisi portofolio kredit yang paling optimal bagi BNI Sentra Kredit Kecil (SKC) Bandung adalah sebagai berikut :

a. Pertanian, Perburuan dan Sarana Pertanian (0,72\%)

b. Pertambangan $(0,00 \%)$

c. Industri Pengolahan $(52,41 \%)$

d. Konstruksi (3,82\%)

e. Perdagangan, Restoran dan Hotel $(22,18 \%)$

f. Pengangkutan, Pergudangan dan Komunikasi (0,89\%)

g. Jasa-jasa Dunia Usaha $(20,00 \%)$

h. Jasa-jasa sosial masyarakat (0,00\%)

Penentuan titik optimal tersebut dengan menggunakan Sharpe Ratio, titik singgung garis CAL dengan kurva efficient frontier merupakan titik dengan Sharpe Ratio yang tertinggi. Hal ini berarti pada titik tersebut lah risk and return yang dihasillkan oleh portofolio kredit Bank BNI Sentra Kredit Kecil (SKC) Bandung paling optimal.

Komposisi portofolio kredit tersebut menghasilkan expected return 0,450\% dengan standar deviasi 0,000112. Jika dibandingkan dengan kondisi saat ini yang berada di luar kurva efficient frontier sehingga portofolio yang ada dinilai tidak efisien. Proporsi saat ini jauh dari kondisi optimal tersebut, sehingga return nya yaitu 0,367\% dibawah kondisi optimal sedangkan standar deviasinya sebesar 0,000270 sangat jauh diatas kondisi optimal.

\section{Pembahasan Hasil Penelitian}

\subsection{Komposisi Portofolio Kredit Pada Bank BNI Sentra Kredit Kecil (SKC) Bandung}

Tabel 2

Perbandingan Komposisi Portofolio Kredit Pada Kondisi Saat Ini dan Kondisi Optimal

\begin{tabular}{|l|r|r|}
\hline \multirow{2}{*}{\multicolumn{1}{|c|}{ Portofolio }} & \multicolumn{2}{c|}{ Komposisi } \\
\cline { 2 - 3 } & \multicolumn{1}{|c|}{ Saat ini } & \multicolumn{1}{c|}{ Optimal } \\
\hline $\begin{array}{l}\text { Pertanian, Perburuan \& sarana } \\
\text { pertanian }\end{array}$ & $0.864 \%$ & $0.715 \%$ \\
\hline Pertambangan & $1.029 \%$ & $0.000 \%$ \\
\hline Industri Pengolahan & $19.645 \%$ & $52.409 \%$ \\
\hline Konstruksi & $21.205 \%$ & $3.818 \%$ \\
\hline Perdagangan, Restoran, \& Hotel & $25.718 \%$ & $22.175 \%$ \\
\hline $\begin{array}{l}\text { Pengangkutan, Pergudangan } \\
\text { \& Komunikasi }\end{array}$ & $1.609 \%$ & $0.888 \%$ \\
\hline Jasa-jasa Dunia Usaha & $29.363 \%$ & $19.995 \%$ \\
\hline
\end{tabular}

\begin{tabular}{|l|r|r|}
\hline \multirow{2}{*}{\multicolumn{1}{|c|}{ Portofolio }} & \multicolumn{2}{c|}{ Komposisi } \\
\cline { 2 - 3 } & \multicolumn{1}{c|}{ Saat ini } & \multicolumn{1}{c|}{ Optimal } \\
\hline Jasa-jasa Sosial Masyarakat & $0.567 \%$ & $0.000 \%$ \\
\hline PORTFOLIO MEAN & $0.367 \%$ & $0.450 \%$ \\
\hline PORTFOLIO SD & 0.000270 & 0.000112 \\
\hline
\end{tabular}

Berdasarkan Tabel 2 tentu sangat sulit bagi Bank BNI Sentra Kredit Kecil (SKC) Bandung untuk mewujudkan atau mendekati kondisi optimal tersebut. Sebagai contoh untuk sektor jasa-jasa sosial masyarakat, karena pada kondisi optimalnya tidak mendapat porsi dalam portofolio yang akan dituju maka seakan-akan seluruh debitur yang ada saat ini diminta untuk melunasi kreditnya. Begitu pula dengan debitur-debitur dari sektor pertambangan. Hal ini tentu tidak mungkin dilakukan, karena bank pada prinsipnya tidak akan meminta debiturnya melunasi sepanjang kinerjanya masih dinilai baik.

Komposisi portofolio kredit yang optimal berdasarkan kurva effient frontier yang terbentuk bukanlah menjadi suatu target yang harus diterapkan atau dicapai melainkan menjadi acuan bagi arah kebijakan pengelolaan kredit pada Bank BNI Sentra Kredit Kecil (SKC) Bandung. Kebijakan tersebut bergantung pada preferensi dari manajemen Bank BNI Sentra Kredit Kecil (SKC) Bandung, misalnya jikka manajemen memiliki preferensi pada return yang lebih besar, maka titik yang dikejar adalah lebih menjauhi sumbu $X$, sedangkan jika ingin memiliki risiko yang lebih kecil maka komposisi yang dituju adalah mendekati sumbu Y. Namun pemilihan pada kombinasi risk-return seperti apa yang diambil sebaiknya masih berada di dalam kurva efficient frontier, jika diluar kurva pencapaiannya akan jauh lebih sulit karena kurva tersebut merepresentasikan kinerja selama periode penelitian.

\subsection{Analisis Komposisi Portofolio Kredit Terhadap Return Dan Risiko Kredit}

Hasil penelitian menunjukkan bahwa komposisi portofolio kredit berpengaruh terhadap return dan risiko kredit sebagai contoh komposisi untuk sektor Jasa-jasa Sosial Masyarakat menunjukkan hasil return terendah dengan risiko tertinggi dan sektor perdagangan menunjukkan hasil return tertinggi dengan risiko terendah.

Dari uraian diatas terlihat bahwa sistem deteksi dini atas portofolio yang dikelola belum dimiliki. Sehingga dapat dikatakan unit bisnis kurang mengenal profil risiko atas portofolio yang dikelolanya secara baik. Pengelolaan risiko 
kredit yang dilakukan masih difokuskan pada pengelolaan risiko individual per nominative debitur dan belum dilakukan dalam perspektif portofolio.

\section{Kesimpulan}

1. Komposisi portofolio kredit Bank BNI Sentra Kredit Kecil (SKC) Bandung pada kondisi saat ini berada di luar kurva efficient frontier artinya portofolio yang ada dinilai tidak efisien yaitu return sebesar 0,367\% dengan standar deviasi sebesar 0,000270.

2. Komposisi portofolio kredit yang optimal pada Bank BNI Sentra Kredit Kecil (SKC) Bandung yaitu komposisi portofolio kredit yang menghasilkan expected return sebesar 0,450\% dengan standar deviasi sebesar 0,000112 .

3. Hasil penelitian menunjukkan bahwa komposisi portofolio kredit berpengaruh terhadap return dan risiko kredit dimana untuk komposisi portofolio kredit yang menghasilkan return yang tinggi akan menghasilkan risiko kredit yang rendah.

\section{Rekomendasi}

1. Bagi peneliti yang akan meneliti lebih lanjut penulis menyarankan agar peneliti dapat meneliti pengaruh komposisi portofolio kredit terhadap return dan risiko kredit dari sisi lain seperti penyebaran portofolio kredit berdasarkan jenis kredit, besaran maksimum kredit, dll.

2. Bagi manajemen Bank BNI Sentra Kredit Kecil (SKC) Bandung penulis menyarankan agar mengambil langkah strategis menyangkut kebijakan yang harus dilaksanakan dalam rangka pengelolaan portofolio kreditnya dan hasil penelitian ini dapat menjadi arahan bagi kebijakan ekspansi kredit pada Bank BNI Sentra Kredit Kecil (SKC) Bandung.

\section{Daftar Pustaka}

Beste, Allison, Dennis Leventhal, Jared Williams, Dr. Qin Lu, 2002. The Markowitz, Model: Selecting an Efficient Investment Portfolio, Lafayette College.

Fabozzi, Frank. J. 1999. Manajemen Investasi (Buku Satu), Salemba Empat, Jakarta.
Sugiyono. 2006. Metode Penelitian Bisnis. Bandung: Alfabeta.

Uma Sekaran. 2006. Metodologi Penelitian untuk Bisnis. Jakarta: Salemba 4. 